\title{
A pharmacogenetic study of patients with schizophrenia from West Siberia gets insight into dopaminergic mechanisms of antipsychotic-induced hyperprolactinemia
}

Diana Z. Osmanova 1,2, Maxim B. Freidin 3,4, Olga Yu. Fedorenko 1,5, Ivan V. Pozhidaev,2, Anastasiia S. Boiko', Natalia M. Vyalova', Vladimir V. Tiguntsev ${ }^{1}$, Elena G. Kornetova', Anton J. M. Loonen ${ }^{6,7}$, Arkadiy V. Semke', Bob Wilffert ${ }^{6,8}$, Nikolay A. Bokhan ${ }^{1,2}$ and Svetlana A. Ivanova ${ }^{1,5^{*}}$

From 11th International Multiconference "Bioinformatics of Genome Regulation and StructurelSystems Biology" - BGRSISB2018

Novosibirsk, Russia. 20-25 August 2018

\section{Abstract}

Background: Hyperprolactinemia (HPRL) is a classical side effect of antipsychotic drugs primarily attributed to blockade of dopamine D2 receptors (DRD2s) on the membranes of lactotroph cells within the pituitary gland. Certain antipsychotic drugs, e.g. risperidone, are more likely to induce HPRL because of relative accumulation within the adenohypophysis. Nevertheless, due to competition for pituitary DRD2s by high dopamine levels may limit antipsychotic-induced HPRL. Moreover, the activity of prolactin-producing lactotrophs also depends on other hormones which are regulated by the extra-pituitary activity of dopamine receptors, dopamine transporters, enzymes of neurotransmitter metabolism and other factors. Polymorphic variants in the genes coding for these receptors and proteins can have functional significance and influence on the development of hyperprolactinemia.

Methods: A set of 41 SNPs of genes for dopamine receptors DRD1, DRD2, DRD3, DRD4, the dopamine transporter SLC6A3 and dopamine catabolizing enzymes MAOA and MAOB was investigated in a population of 446 Caucasians (221 males/225 females) with a clinical diagnosis of schizophrenia (according to ICD-10: F20) with and without HPRL who were treated with classical and/or atypical antipsychotic drugs. Additive genetic model was tested and the analysis was carried out in the total group and in subgroup stratified by the use of risperidone/paliperidone.

Results: One statistically significant association between polymorphic variant rs 1799836 of MAOB gene and HPRL in men was found in the total group. Furthermore, the rs40184 and rs3863145 variants in SLC6A3 gene appeared to be associated with HPRL in the subgroup of patients using the risperidone/paliperidone, but not with HPRL induced by other antipsychotic drugs.

(Continued on next page)

\footnotetext{
* Correspondence: ivanovaniipz@gmail.com

${ }^{1}$ Mental Health Research Institute, Tomsk National Research Medical Center

of the Russian Academy of Sciences, Aleutskaya str., 4, Tomsk, Russian

Federation634014

${ }^{5}$ National Research Tomsk Polytechnic University, Lenin Avenue, Tomsk,

Russian Federation30

Full list of author information is available at the end of the article
}

(c) The Author(s). 2019 Open Access This article is distributed under the terms of the Creative Commons Attribution 4.0 International License (http://creativecommons.org/licenses/by/4.0/), which permits unrestricted use, distribution, and reproduction in any medium, provided you give appropriate credit to the original author(s) and the source, provide a link to the Creative Commons license, and indicate if changes were made. The Creative Commons Public Domain Dedication waiver (http://creativecommons.org/publicdomain/zero/1.0/) applies to the data made available in this article, unless otherwise stated. 
(Continued from previous page)

Conclusions: Our results indicate that genetic variants of MAOB and SLC6A3 may have consequences on the modulation of prolactin secretion. A further search for genetic markers associated with the development of antipsychotic-related hyperprolactinemia in schizophrenic patients is needed.

Keywords: Dopamine receptors genes, Dopamine transporter SLC6A3, Monoamine oxidase (MAO), Antipsychotics, Hyperprolactinemia

\section{Background}

Schizophrenia is a serious polymorphic mental disorder, characterized by positive (e.g., hallucinations, delusions), negative (affective flattening, social withdrawal) and cognitive symptoms (disorders of attention, working memory deficits). Treatment of schizophrenic illness usually involves the long-term usage of antipsychotic drugs [1], which have both therapeutic and side effects, related to antagonism to D2 receptors. One of the common side effects of these drugs is hyperprolactinemia [2, 3]. HPRL-related phenomena may lead to additional social stigmatization of the patient with schizophrenia, which reduces the compliance of patients to therapy and increases the cost of treatment. HPRL has short- and long-term consequences that can seriously affect quality of life: menstrual disturbances, galactorrhea, sexual dysfunction, gynecomastia, infertility, and possibly decreased bone mineral density.

Prolactin (PRL) is a polypeptide hormone that contains 199 amino acids and is categorized as part of the growth hormone family [4]. Prolactin secretion is under a complex neuroendocrine control, in which various agents participate: neurotransmitters, biologically active neuropeptides, hormones of peripheral endocrine glands. Synthesis and secretion of prolactin are carried out by lactotrophs of the pituitary gland, which constitute an average of $20-50 \%$ of the total cell population of the pituitary cells [5].

Factors involved in the regulation of prolactin secretion can be divided into two groups: 1 . prolactin-inhibiting dopamine (DA), gamma-aminobutyric acid, gastrin, somatostatin, gonadotropin-binding protein and 2. prolactinstimulating - serotonin, thyrotropin-releasing hormone (TRH), gonadotropin-releasing hormone (TRG), vaso-intestinal peptide, opiates, neurotensin and substance P, oxytocin, angiotensin $2[6,7]$.

Dopamine holds a predominant role in the regulation of prolactin secretion. Dopamine, which is released by tuberoinfundibular neurons, normally acts at specific receptors on lactotrophes to tonically inhibit prolactin secretion and maintain physiologically normal prolactin levels in the blood [8]. These dopamine receptors located on lactotroph membranes belong to the D2 subclass of the dopamine receptor family $[9,10]$.
The hypothalamic dopaminergic neurons, which provide DA to the anterior pituitary gland, are themselves regulated by feedback from PRL through a 'short-loop feedback mechanism'. Elevation of serum levels of prolactin increases hypothalamic dopamine synthesis [11] and the concentration of dopamine in hypothalamic-pituitary portal blood [12].

All typical antipsychotic medications are associated with sustained hyperprolactinemia due to their high affinity for the D2 receptor and their slow dissociation from the receptor once bound, but the atypicals clozapine and quetiapine differ quite dramatically in their propensity to cause prolonged high prolactin levels, because they are loosely bound to D2 receptors [13]. The dopamine D2 partial receptor agonist aripiprazole is even capable to reduce prolactin levels [3].

Another way to explain hyperprolactinemia is the ability of antipsychotic-drugs to cross the blood-brain barrier and to affect the activity of prolactin-inhibiting and prolactin-stimulating factors. This capacity partly depends upon affinity to the drug efflux transporter P-glycoprotein, which prevents drugs to pass the blood brain barrier $[14,15]$. This may result in relatively accumulation within the pituitary gland in comparison to brain tissue which is protected by the blood brain barrier [16].

PRL elevations with antipsychotic medication generally are dose dependent. However, antipsychotics having a high potential for PRL elevation (amisulpride, sulpriride, risperidone and paliperidone) can have a profound impact on PRL levels even at relatively low doses, while PRL levels with antipsychotics having a minimal effect on PRL, in most cases, can remain unchanged (quetiapine) or reduce (aripiprazole) over all dosages. Although tolerance and decreases in PRL values after long-term administration of PRL-elevating antipsychotics can occur, the elevations, in most cases, remain above the upper limit of normal [3].

In conclusion, antipsychotic drugs may affect prolactin release directly by blocking dopamine D2 receptors on lactotrophs, but modulate this activity by affecting dopamine levels within the hypothalamic-pituitary portal blood. Moreover, antipsychotics can modulate intracerebral mechanisms involved in the regulation of prolactin release. As the main targets for the therapeutic actions 
of neuroleptics in schizophrenia are components of cerebral dopamine and - to a lesser extent - serotonin neurotransmission, the authors aimed at identifying the association of neuroleptic hyperprolactinemia with polymorphism of genes that determine the activity of various components of dopaminergic transmission - enzymes that catalyze the synthesis and metabolism of dopamine, its storage, release into the synaptic cleft and reverse capture, as well as the structure of its receptors.

According to the literature data genetic variants of dopaminergic receptors, transporters and enzyme may have functional consequences on the respond of antipsychotic treatment and development of side effects of therapy.

In the structure of the dopamine receptor D1 (localized on the postsynaptic membrane), two single nucleotide polymorphisms associated with the risk of developing schizophrenia have been identified: G198A and G1263A [17]. These substitutions are synonymous, they do not lead to a change in the amino acid composition of the receptor, but presumably may have an effect on gene expression, particularly on the formation of heterodimeric forms of the dopamine receptor consisting of the D1 and D2 subunits [18]. In several studies rs4532 polymorphism in DRD1 is considered as a potential pharmacogenomic marker for treatment response to antipsychotic drugs [19, 20].

At least 23 single nucleotide polymorphisms within $D R D 2$ were evaluated to determine whether any of them controlled DRD2 expression [21]. The polymorphism of D2 receptors Taq1A, represented by two alleles - A1 and $A 2$ in the region of the promoter that regulates gene expression, has been studied most. It was found that reduced dopamine D2 receptor binding in the human striatum associated with the A1 allele [22]. The association of Taq1A polymorphism with schizophrenia was reported [23], it was later shown that $A 1$ allele is associated with a predisposition to the development of dyskinesias on the background treatment with neuroleptics [24]. The study of this polymorphism is complicated by the fact that this site is "concurrently" promoted by another, located next to the gene - ANNK1, which encodes protein kinase $R K K 2$. DRD2/ANKK1 genotypes are associated with susceptibility to second generation antipsychotic-induced akathisia [25].

Polymorphism of other subtypes of dopamine receptors of the second type, D3 and D4, also, according to a number of researchers, is associated with a risk of developing schizophrenia spectrum disorders [26-28]. There is evidence that the several polymorphic variants in gene D3 receptor are associated with a risk of developing schizophrenia [29], as well as with a decrease in the level of implementation cognitive tasks [30] and antipsychotic induced tardive dyskinesia [31].
The dopamine transporter gene (SLC6A3) appears to be one of the most important candidate genes for affecting mental disorders, as it is the target of many psychostimulants that cause symptoms similar to the positive symptoms of schizophrenia. Controversial information was obtained by studying the effect of polymorphism in SLC6A3 on pharmacogenetics of adverse events in schizophrenia treatment $[32,33]$.

Dopamine can be degraded in several ways, in which enzymes such as monoamine oxidase (MAO) and catechol-O-methyltransferase (COMT) play a leading role. There are two isoforms of monoamine oxidase MAOA and MAOB, whose genes are located on the $\mathrm{X}$ chromosome. MAOA catalyzes monoamine neurotransmitters including 5-hydroxytryptamine (5-HT, serotonin), norepinephrine and dopamine, while MAOB deaminates 2-phenylethylamine and also dopamine [34]. The association of polymorphic variants of the $M A O A$ gene with features of an alarming series, such as neuroticism and negative affect, is described. Changes in the sequence of nucleotides in the promoter region of the $M A O A$ gene are associated with a reduced level of expression of this gene and may be associated with an increased level of aggression and impulsivity compared to a typical $M A O A$ promoter that determines the normal level of expression [35].

There is a series of studies with the search for associations of polymorphisms of the genes of dopamine receptors and metabolizing enzymes in various combinations and response or side effects to antipsychotic therapy: DRD2 and dopamine transporter SLC6A3 [36]; DRD1, DRD2, DRD3 and COMT [37]; DRD1, COMT, DRD2, and $D R D 3$ [38].

\section{Methods}

Based upon reviewing the literature we selected a set of 26 polymorphisms in dopamine receptors genes (DRD1, $D R D 2, D R D 3, D R D 4), 12$ polymorphic variants of dopamine transporter $S L C 6 A 3$, as well as 3 polymorphisms of monoamine oxidase $\mathrm{A}$ and $\mathrm{B}$ and here we present new data on the association between them and HPRL in antipsychotic drug-treated patients with schizophrenia from West Siberia, Russian Federation.

\section{Patients}

The study population was previous described by Ivanova et al. $[39,40]$. The work was carried out in accordance with The Code of Ethics of the World Medical Association (Declaration of Helsinki 1975, revised in Fortaleza, Brazil, 2013) for experiments involving humans. The patients in this study were retrieved from three psychiatric hospitals in Tomsk, Kemerovo, and Chita oblasts in Siberia. The inclusion criteria were a clinical diagnosis of schizophrenia according to ICD-10 (F20), patients aged 
18-75 years, Caucasian physical appearance and a signed informed consent form to participate in the study after approval from the study (protocol N63/7.2014) from the Local Bioethics Committee of the Mental Health Research Institute. Exclusion criteria for all patients were non-Caucasian physical appearance (e.g., Mongoloid, Buryats or Khakassians), pregnancy or relevant gynecological and endocrine (thyroid) disorders, relevant pharmacological withdrawal symptoms or organic brain disorders (e.g., epilepsy, Parkinson's disease), the presence of acute and chronic infectious, inflammatory, autoimmune diseases, as well as persons with active oncological diseases, accompanied by an increased level of prolactin on the blood.

The total sample consisted of 446 patients (221 males/ 225 females). The women were significantly older ( $p=$ 2.6e-8, Mann-Whitney test (MWT)) than the men (mean \pm SD $45.2 \pm 13.9$ vs. $37.8 \pm 11.9$ years). Among the women, 86 were $>50$ years of age. Women suffered from the disease for a significantly longer $(p=0.0002$, MWT) period of time ( $17.6 \pm 12.5$ vs. $13.1 \pm 10.0$ years). The median antipsychotic daily dose was $500 \mathrm{mg}$ CPZeq (quartiles 280; 750) in men and $320 \mathrm{mg}$ CPZeq (quartiles 200; $750)$ in women ( $\mathrm{p}=0.0002$, MWT).

A total of 227 patients suffered from HPRL (98 males/ 129 females) according to the predefined criteria [3, 39]. Demographic and clinical features of patients with schizophrenia with and without hyperprolactinemia are presented in Table 1.

One hundred ninety-one patients were treated with conventional antipsychotics in oral and/or long-acting formulations. The most common conventional antipsychotic was haloperidol, which was used in 110 patients, but other treatments included oral chlorpromazine, chlorprothixene, trifluoperazin, and zuclopenthixol, and/or long-acting formulations of haloperidol-, zuclopenthixol-, and flupenthixol-decanoate. A total of 176 patients were treated with atypical antipsychotics: risperidone, clozapine, quetiapine, olanzapine, amisulpride, paliperidone, and sertindole. Different combinations of classical and atypical drugs were used by 79 patients. 76 patients were treated with risperidone/paliperidone.

To compare antipsychotic medications, all dosages were converted into chlorpromazine equivalents (CPZeq) [41].

Blood samples were taken $8 \mathrm{~h}$ after overnight fasting in tubes containing EDTA for DNA extraction and in tubes with CAT (clot activator) to obtain serum (BD Vacutainer). Blood with EDTA was stored in several aliquots at $-20^{\circ} \mathrm{C}$ until DNA isolation. Blood samples with CAT were centrifuged for $30 \mathrm{~min}$ at $1500 \mathrm{rpm}$ at $4{ }^{\circ} \mathrm{C}$ to obtain serum.

\section{Hormone analysis}

The PRL concentration was measured in serum using the AccuBind ELISA Microwells kit (Monobind Inc., USA). In this microplate immunoenzymatic assay, the ELISA has a sensitivity of $0.004 \mathrm{ng} /$ well. This is equivalent to a sample containing $0.150 \mathrm{ng} / \mathrm{ml}$ PRL. The upper limits for normal PRL concentration were set at $\leq 20 \mathrm{ng} / \mathrm{ml}$ for men and $\leq$ $25 \mathrm{ng} / \mathrm{ml}$ for non-pregnant, non-nursing women $[39,40]$. For women of reproductive age, blood was when possibly taken in the follicular phase of the menstrual cycle. This corresponds to the criteria for HPRL applied by Kelly et al. [42] and Peuskens et al. [3].

\section{DNA analysis}

DNA was isolated from the leukocytes in whole peripheral blood from patients with mental disorders using the standard phenol-chloroform method.

Genotyping was carried out for DRD1, DRD2, DRD3, $D R D 4$, and SLC6A3 genes in the Genome Analysis Facility, Dept. Genetics (Head: Prof. Dr. C. Wijmenga), University Medical Center Groningen on the MassARRAY Analyzer 4 (Agena Bioscience ${ }^{\mathrm{m}}$ ) using the set SEQUENOM Consumables iPLEX Gold 384. DNA sample preparation for SEQUENOM MassARRAY ${ }^{\circ}$ Analyzer 4 includes several steps: a standard PCR reaction to obtain the amplification products, a shrimp alkaline phosphatase (SAP) reaction to neutralize the unincorporated dNTPs in the amplification products, the PCR iPLEX Gold extension reaction, and then placing the samples on a special chip (SpectroCHIP Array) using NanoDispenser RS1000 prior to loading them into the analyzer. SNPs in $M A O A, M A O B$ genes were genotyped in the Mental Health Research Institute, Tomsk National Research Medical Center of the Russian Academy of Sciences, using the fluorogenic 5 '-exonuclease TaqMan technology performed on the real-time polymerase chain reaction system "StepOnePlus" (Applied Biosystems, USA).

We selected a set of 26 SNPs from the following dopamine receptors genes: DRD1, DRD2, DRD3, DRD4 (Table 2), 12 polymorphic variants of dopamine transporter

Table 1 Demographic and clinical features of patients with schizophrenia with and without HPRL

\begin{tabular}{llll}
\hline Feature & Patients with HPRL, $n=227$ & Patients without HPRL, $n=219$ & $p$-value \\
\hline Age & $49.19 \pm 13.19$ & $42.94 \pm 13.56$ & 0.031 \\
Male/Female & $98 / 129$ & $123 / 96$ & 0.006 \\
Dose of antipsychotics into chlorpromazine equivalent & $400(225 ; 750)$ & $400(280 ; 750)$ & 0.074 \\
Duration of the disease & $11.0(4.0 ; 22.0)$ & $14.0(8.0 ; 22.0)$ & 0.041 \\
\hline
\end{tabular}


Table 2 List of analyzed polymorphic variants of dopamine receptor genes

\begin{tabular}{|c|c|c|c|c|c|}
\hline Gene & SNP & Chromosome & Chromosome position & Alleles & Minor Allele Frequency \\
\hline DRD1 & rs4532 & 5 & $174,870,150$ & $\mathrm{~T} / \mathrm{C}$ & 24.4 \\
\hline$D R D 2$ & rs6275 & 11 & $113,283,477$ & $C / T$ & 47.3 \\
\hline DRD2 & rs6277 & 11 & $113,283,459$ & $C / T$ & 24.4 \\
\hline$D R D 2$ & rs1076560 & 11 & $113,283,688$ & C/A & 22.9 \\
\hline DRD2 & rs1801028 & 11 & $113,283,484$ & $C / G$ & 3.1 \\
\hline DRD2 & rs4245147 & 11 & $113,318,007$ & $\mathrm{~T} / \mathrm{C}$ & 45.4 \\
\hline DRD2 & rs2283265 & 11 & $113,285,536$ & $\mathrm{G} / \mathrm{T}$ & 22.7 \\
\hline DRD2 & rs6279 & 11 & $113,281,073$ & $\mathrm{G} / \mathrm{C}$ & 47.8 \\
\hline DRD2 & rs1076562 & 11 & $113,296,008$ & $\mathrm{G} / \mathrm{A}$ & 42.1 \\
\hline DRD2 & rs2734842 & 11 & $113,280,274$ & $\mathrm{G} / \mathrm{C}$ & 46.7 \\
\hline DRD2/ANKK1 & rs2734849 & 11 & $113,270,160$ & $\mathrm{~T} / \mathrm{C}$ & 24.5 \\
\hline DRD3 & rs11721264 & 3 & $113,879,404$ & $\mathrm{G} / \mathrm{A}$ & 41.4 \\
\hline DRD3 & rs167770 & 3 & $113,879,562$ & $A / G$ & 42.2 \\
\hline DRD3 & rs3773678 & 3 & $113,870,078$ & $C / T$ & 32.0 \\
\hline DRD3 & rs963468 & 3 & $113,862,887$ & $\mathrm{G} / \mathrm{A}$ & 27.2 \\
\hline DRD3 & rs7633291 & 3 & $113,887,068$ & $\mathrm{~T} / \mathrm{G}$ & 22.4 \\
\hline DRD3 & rs2134655 & 3 & $113,858,201$ & $\mathrm{G} / \mathrm{A}$ & 20.3 \\
\hline DRD3 & rs9817063 & 3 & $113,847,108$ & $C / T$ & 42.8 \\
\hline DRD3 & rs324035 & 3 & $113,868,854$ & C/A & 40.2 \\
\hline DRD3 & rs1800828 & 3 & $113,891,549$ & $\mathrm{G} / \mathrm{C}$ & 22.2 \\
\hline DRD3 & rs 167771 & 3 & $113,876,275$ & $A / G$ & 41.1 \\
\hline DRD3 & rs6280 & 3 & $113,890,815$ & $\mathrm{~T} / \mathrm{C}$ & 48.6 \\
\hline DRD3 & rs1587756 & 3 & $113,902,751$ & T/C & 14.6 \\
\hline DRD4 & rs3758653 & 11 & 636,399 & $\mathrm{~T} / \mathrm{C}$ & 24.7 \\
\hline DRD4 & rs11246226 & 11 & 641,191 & $\mathrm{~A} / \mathrm{C}$ & 47.7 \\
\hline DRD4 & rs936461 & 11 & 636,496 & $\mathrm{G} / \mathrm{A}$ & 45.7 \\
\hline
\end{tabular}

SLC6A3 and 3 polymorphisms of genes $M A O A$ and $M A O B$ (Table 3).

\section{Statistical analysis}

We analyzed associations between the polymorphisms and HPRL using logistic regression models including HPRL as a dependent categorical variable and polymorphisms as the predictors. Age, sex, and CPZeq were used as covariates. Additive genetic model was tested and Odds ratios (OR) along with 95\% confidence intervals (CI) were calculated regarding the risk of HPRL for the rare allele vs common allele. Prior to the analysis, the polymorphisms were filtered out in case of minor allele frequency below $5 \%$ or Hardy-Weinberg equilibrium (HWE) $p$-value below 0.001. HWE was tested using Fisher's exact test except for SNPs located in the X-chromosomal (MAOA, MAOB). The Mann-Whitney test was used to compare qualitative traits and $\chi^{2}$ test for categorical traits.
All calculations were performed in the R statistical environment using basic $\mathrm{R}$ functions and the SNPassoc package [43].

\section{Results}

From the list of 38 SNPs studied of dopamine receptor genes and SLC6A3 genes we excluded 4 SNPs (rs6275, rs6347, rs2550956, rs11133767) with Hardy-Weinberg equilibrium $p$-value $<0.001$, thus leaving 34 SNPs for the analysis of associations with HPRL. In the total group of patients none of the studied genetic markers localized in autosomal chromosomes are associated with HPRL (Additional file 1).

Polymorphic variants of monoamine oxidase genes are localized in the $\mathrm{X}$ chromosome. Taking into account the hemizygotic status of X-chromosomal markers for men, the analysis of these markers was carried out separately in men and women. Using the logistic regression analysis with age and CPZeq as covariate we found the association of rs1799836 with HPRL in men (Table 4). Allele 
Table 3 List of analyzed polymorphic variants of the dopamine transporter gene and the monoamine oxidase genes

\begin{tabular}{|c|c|c|c|c|c|}
\hline Gene & SNP & Chromosome & Chromosome position & Alleles & Minor Allele Frequency \\
\hline SLC6A3 & rs3756450 & 5 & $1,448,148$ & T/C & 34.9 \\
\hline SLC6A3 & rs2550956 & 5 & $1,447,841$ & $\mathrm{~T} / \mathrm{C}$ & 17.3 \\
\hline SLC6A3 & rs6347 & 5 & $1,411,412$ & $A / G$ & 29.8 \\
\hline SLC6A3 & rs2617605 & 5 & $1,442,521$ & $A / G$ & 25.6 \\
\hline SLC6A3 & rs3863145 & 5 & $1,392,711$ & $\mathrm{C} / \mathrm{T}$ & 16.8 \\
\hline SLC6A3 & rs250686 & 5 & $1,425,159$ & $\mathrm{G} / \mathrm{A}$ & 40.7 \\
\hline SLC6A3 & rs464049 & 5 & $1,423,905$ & $\mathrm{C} / \mathrm{T}$ & 39.1 \\
\hline SLC6A3 & rs4975646 & 5 & $1,433,401$ & $\mathrm{G} / \mathrm{A}$ & 13.4 \\
\hline SLC6A3 & rs1048953 & 5 & $1,438,174$ & $C / T$ & 14.6 \\
\hline SLC6A3 & rs11133767 & 5 & $1,401,580$ & $A / G$ & 31.8 \\
\hline SLC6A3 & rs27048 & 5 & $1,412,645$ & $C / \mathrm{T}$ & 32.1 \\
\hline SLC6A3 & rs40184 & 5 & $1,395,077$ & $\mathrm{G} / \mathrm{A}$ & 41.3 \\
\hline$M A O A$ & rs6323 & $x$ & $43,591,036$ & $\mathrm{G} / \mathrm{T}$ & 37.5 \\
\hline$M A O A$ & rs1137070 & $x$ & $43,603,391$ & $C / T$ & 44.8 \\
\hline$M A O B$ & rs1799836 & $x$ & $43,627,999$ & $A / G$ & 45.6 \\
\hline
\end{tabular}

and genotype frequencies are shown in Additional file 2. A protective effect of the rs1799836*A allele against HPRL development was observed.

Due to the fact that according to literature data, HPRL is significantly more common in patients receiving risperidone/paliperidone, the next step was the analysis in the subgroup of patients using the risperidone/paliperidone. Using logistic regression with age, gender, and CPZeq as covariates we found that the rs40184 and rs3863145 variants in SLC6A3 gene appeared to be associated with HPRL in this subgroup of patients (Table 5). Allele and genotype frequencies are shown in Additional file 3. The rs40184* A and the rs $3863145^{*} \mathrm{C}$ alleles were found to exhibit a protective effect, reducing the risk of hyperprolactinemia in carriers of these genotypes. Notably, the both SNPs are in some linkage disequilibrium LD, therefore, their association with the HPRL is bound by the same

Table 4 Analysis of association between HPRL and the polymorphisms of MAO genes for all patients divided by gender

\begin{tabular}{llllll}
\hline Gender & SNP & OR & $\begin{array}{l}95 \% \mathrm{Cl} \\
\text { Lower bound }\end{array}$ & $\begin{array}{l}95 \% \mathrm{Cl} \\
\text { Upper bound }\end{array}$ & $p$-value \\
\hline Females & rs1799836 & 0.939 & 0.644 & 1.369 & 0.744 \\
& rs1137070 & 0.757 & 0.497 & 1.153 & 0.195 \\
& rs6323 & 0.786 & 0.512 & 1.208 & 0.273 \\
Males & rs1799836 & 0.748 & 0.561 & 0.998 & $\mathbf{0 . 0 4 8 ^ { * }}$ \\
& rs1137070 & 1.279 & 0.942 & 1.737 & 0.115 \\
& rs6323 & 1.315 & 0.970 & 1.782 & 0.078 \\
\hline
\end{tabular}

Logistic regression analysis was used to test additive genetic model for association between HPRL and the MAO genes polymorphisms in males and females separately adjusting for age and CPZeq. OR - odds ratio; $\mathrm{Cl}$ - lower and upper bound $95 \%$ confidence intervals. ORs are reported for the risk of HPRL attributable to the rare allele vs common allele

*Values are deemed to have significance haplotype (Additional file 4). Polymorphisms in $M A O$ genes were not associated with hyperprolactinemia in the studied subgroup (Additional file 5).

\section{Discussion}

We studied the association between polymorphisms of genes relevant for dopaminergic neurotransmission such as receptors, transporter, and enzymes with antipsychotic drug-induced HPRL in white patients with schizophrenia from Siberia. We excluded patients with physiological or pathological conditions that may affect PRL secretion and corrected for variables related to PRL secretion and/or that may determine antipsychotic drug load. The assessment of a possible association is considered the first step in discovering the possible functional consequences of genetic variations. We distinguished HPRL for men and women. The studied women were significantly older than the men and patients with HPRL were more often female than those without. Premenopausal women have significantly higher PRL levels than postmenopausal female persons, who have not significantly different levels in comparison to men [44-46]. This might be related to modulation of PRL dynamics by estrogen levels [44]. The gender and age differences between the patients with and without HPRL may have falsely decreased the actual prevalence of drug-induced HPRL in the HPRL group in comparison to non-HPRL patients. However, when only male patients were studied significant association was found with one polymorphism rs1799836 of $M A O B$ gene.

$M A O B$, located adjacent to $M A O A$ on the opposite strand at chromosome Xp11.23, is involved in the breakdown of dopamine in the brain [34]. MAO-B is widely 
Table 5 Analysis of association between HPRL and the genetic polymorphisms in patients from risperidone/paliperidone group

\begin{tabular}{|c|c|c|c|c|c|}
\hline Gene & SNP & OR & $\begin{array}{l}\text { 95\% Cl } \\
\text { Lower bound }\end{array}$ & $\begin{array}{l}95 \% \mathrm{Cl} \\
\text { Upper bound }\end{array}$ & $p$-value \\
\hline DRD1 & rs4532 & 0.522 & 0.216 & 1.261 & 0.148 \\
\hline DRD2 & rs1076562 & 0.490 & 0.192 & 1.249 & 0.135 \\
\hline DRD2 & rs4245147 & 1.148 & 0.519 & 2.541 & 0.733 \\
\hline DRD2 & rs2283265 & 0.900 & 0.301 & 2.686 & 0.850 \\
\hline DRD2 & rs2734842 & 0.472 & 0.187 & 1.194 & 0.113 \\
\hline DRD2 & rs6277 & 2.081 & 0.864 & 5.011 & 0.102 \\
\hline DRD2 & rs6279 & 0.434 & 0.164 & 1.145 & 0.092 \\
\hline DRD2 & rs1076560 & 0.969 & 0.327 & 2.878 & 0.955 \\
\hline DRD2/ANKK1 & rs2734849 & 1.833 & 0.781 & 4.302 & 0.164 \\
\hline DRD3 & rs11721264 & 2.042 & 0.677 & 6.156 & 0.205 \\
\hline DRD3 & rs2134655 & 0.659 & 0.203 & 2.140 & 0.488 \\
\hline DRD3 & rs963468 & 0.647 & 0.251 & 1.666 & 0.367 \\
\hline DRD3 & rs167771 & 1.150 & 0.244 & 5.414 & 0.859 \\
\hline DRD3 & rs324035 & 1.719 & 0.380 & 7.783 & 0.482 \\
\hline DRD3 & rs167770 & 1.963 & 0.622 & 6.195 & 0.250 \\
\hline DRD3 & rs7633291 & 2.462 & 0.640 & 9.473 & 0.190 \\
\hline DRD3 & rs9817063 & 1.635 & 0.626 & 4.270 & 0.316 \\
\hline DRD3 & rs1587756 & 2.407 & 0.489 & 11.861 & 0.280 \\
\hline DRD3 & rs1800828 & 2.813 & 0.739 & 10.711 & 0.129 \\
\hline DRD3 & rs3773678 & 1.556 & 0.326 & 7.412 & 0.579 \\
\hline DRD3 & rs6280 & 2.153 & 0.668 & 6.947 & 0.199 \\
\hline DRD4 & rs3758653 & 1.403 & 0.410 & 4.806 & 0.590 \\
\hline DRD4 & rs936461 & 1.500 & 0.577 & 3.895 & 0.405 \\
\hline DRD4 & rs11246226 & 2.421 & 0.955 & 6.142 & 0.063 \\
\hline SLC6A3 & rs27048 & 1.419 & 0.660 & 3.054 & 0.370 \\
\hline SLC6A3 & rs3756450 & 1.373 & 0.512 & 3.684 & 0.529 \\
\hline SLC6A3 & rs40184 & 0.341 & 0.137 & 0.852 & $0.021^{*}$ \\
\hline SLC6A3 & rs4975646 & 0.640 & 0.258 & 1.589 & 0.336 \\
\hline SLC6A3 & rs2617605 & 0.880 & 0.337 & 2.299 & 0.794 \\
\hline SLC6A3 & rs464049 & 0.538 & 0.209 & 1.384 & 0.199 \\
\hline SLC6A3 & rs1048953 & 0.823 & 0.337 & 2.008 & 0.668 \\
\hline SLC6A3 & rs250686 & 0.563 & 0.214 & 1.482 & 0.245 \\
\hline SLC6A3 & rs3863145 & 0.362 & 0.135 & 0.970 & $0.043^{*}$ \\
\hline
\end{tabular}

Logistic regression analysis was used to test an additive genetic model for association between HPRL and the polymorphisms in adjusting for age, sex and CPZeq. OR - odds ratio; $\mathrm{Cl}$ - lower and upper bound $95 \%$ confidence intervals. ORs are reported for the risk of HPRL attributable to the rare allele vs common allele

*Values are deemed to have significance

distributed within the brain with moderate levels within the adenohypophysis - where MAO-A is low - and hypothalamus $[47,48]$. A non-coding single nucleotide polymorphism rs1799836 in intron 13 is associated with Parkinson's disease [49, 50], schizophrenia [51] and is also significantly associated with reduced negative emotionality [52]. Further, a case-control study by Gasso et al. indicates that the $\mathrm{G}$ allele is a risk factor for developing schizophrenia in a Spanish population [53].

Kang S.G. et al., reported that males schizophrenic patients with $M A O A$ 3-repeat $\mathrm{uVNTR}$ and $M A O B$ A644 genotype has higher association with antipsychotic-induced restless leg syndrome [54].

A. C. Need et al. (2006) studied whether obesity is associated with genetic variants that increase the availability of dopamine. Low activity genotypes at both the $M A O A$ and $M A O B$ loci - showed a relative risk for obesity of 5.01 [55]. Antipsychotic-induced weight gain, including as a consequence of increasing the level of prolactin, can be a particular problem of in schizophrenia treatment, often causing non-compliance and consequent relapse. It is possible that functional variants in the $M A O A$ and $M A O B$ genes could predispose to antipsychotic-induced weight gain in patients with schizophrenia.

Our preliminary hypothesis was that genetic variants of dopamine receptors may have functional consequences on the modulation of PRL secretion and may play an important role in the development of hyperprolactinemia, but the results of the study indicate that there is no association in the group of patients.

However we found that rs40184 and rs3863145 of SLC6A3 gene are associated with risperidone/paliperidone induced HPRL, but not with HPRL induced by other antipsychotic drugs. The solute carrier family 6 (neurotransmitter transporter), member 3 (SLC6A3) gene encodes the dopamine transporter DAT. The difference between risperidone/paliperidone and other antipsychotics might indicate that, although dopamine transporters are present within the adenohypophysis [56] and may have a role in prolactin secretion [57], the pharmacological mechanism related to this association is less likely on the level of the pituitary gland (which is outside the blood-brain-barrier) but localized within the brain itself. Risperidon/paliperidone relatively accumulates within the pituitary gland in comparison to other antipsychotics [16] and thus can be expected to bind to a higher extend to dopamine D2 receptors there.

The DAT protein is expressed in the membrane of neurons, where it transports dopamine from the synaptic cleft back into neurons for reuse. SLC6A3 plays a critical role in controlling dopamine transmission (spatial and temporal domains) through the accumulation of dopamine in extracellular space which is major site of action of psychostimulant drugs [58-60]. The results of several studies indicate that altered SLC6A3 functioning may lead to inter-individual variability of response to antipsychotic drug treatment. Sjoholm H. et al. (2004) [61] reported increased number of SLC6A3 binding sites in the schizophrenia patients who were being treated with 
dopamine D2-receptor blocking antipsychotics. Single locus analysis showed significant association of nine variants from SLC6A3, PIP4K2A and BDNF genes with incomplete antipsychotic response in schizophrenia patients with high severity [62]. The multifactor-dimensionality reduction approach identified gene-gene interaction among $B D N F$ rs7103411-BDNF_rs1491851-SLC6A3_rs40184 in severely ill incomplete responders [62]. Hence, at least some intracerebral pharmacological effects of altered $S C L 6 A 3$ functioning can be expected and these may also influence PRL secretion.

Our new data could be taken into account when therapy with risperidone/paliperidone or different antipsychotic therapy is considered regarding the risk of developing HPRL.

\section{Conclusions}

In conclusion, we found an association of antipsychotic-induced HPRL with rs1799836 of the $M A O B$ gene in (hemizygous) men and rs40184 and rs3863145 variants in the SLC6A3 gene which codes for the dopamine transporter in patients using risperidone/ paliperidone. Strength of our study is the relatively large patient population and careful assessment of hyperprolactinemia. A relative weakness is the sex difference between the HPRL versus non-HPRL groups and the relatively high age of women as this may increase the number of post-menopausal women in the HPRL-group. However, this also makes the associations which we found more likely to exist. A further search for genetic markers associated with the development of antipsychotic-related hyperprolactinemia in schizophrenic patients is needed.

\section{Additional files}

Additional file 1: Table S1. Logistic regression analysis for HPRL as a dependent categorical variable and polymorphisms as the predictors and age, sex, CPZeq as covariates for all patients. (DOC $65 \mathrm{~kb}$ )

Additional file 2: Table S2. Genotype and allele frequencies for MAO gene polymorphisms. (DOC $45 \mathrm{~kb}$ )

Additional file 3: Table S3. Genotype and allele frequencies for all polymorphisms of studied genes in the subgroup of patients using the risperidone/paliperidone. (DOC $275 \mathrm{~kb}$ )

Additional file 4: Table S4. Lewontin's D' statistics to measure pairwise linkage disequilibrium between SLC6A3 SNPs. (XLS $40 \mathrm{~kb}$ )

Additional file 5: Table S5. Analysis of association between HPRL and polymorphisms in MAO genes for female/male patients in risperidone/ paliperidone group. (DOC $34 \mathrm{~kb}$ )

\section{Abbreviations}

Cl: Lower and upper bound 95\% confidence intervals; COMT: Catechol-Omethyltransferase; CPZeq: Chlorpromazine equivalents; DA: Dopamine; DRD2s: Dopamine receptor D2; HPRL: Hyperprolactinemia; HWE: HardyWeinberg equilibrium; ICD-10: International Statistical Classification of Diseases and Related Health Problems 10th Revision; MAO: Monoamine oxidase; MWT: Mann-Whitney test; OR: Odds ratio; PRL: Prolactin; SNP: Single nucleotide polymorphism; TRG: Gonadotropin-releasing hormone;

TRH: Thyrotropin-releasing hormone

\section{Acknowledgements}

This work resulted from a collaboration between the Mental Health Research Institute in Tomsk and the Groningen Research Institute of Pharmacy (GRIP) of the University of Groningen. The Russian part is carried out within the framework of Tomsk Polytechnic University Competitiveness Enhancement Program.

\section{Funding}

This work was in part supported by the Russian Foundation for Basic Research, grant \# 17-29-06035 and by the comprehensive program of fundamental scientific research of the SB RAS "Interdisciplinary Integrated Studies", project No.30.

Publication cost was covered by the Russian Foundation for Basic Research, grant \# 17-29-06035.

\section{Availability of data and materials}

The datasets used and analyzed during the current study are available from the corresponding author on reasonable request.

\section{About this supplement}

This article has been published as part of BMC Medical Genetics Volume 20 Supplement 1, 2019: Selected articles from BGRSISB-2018: medical genetics.

The full contents of the supplement are available online at https:// bmcmedgenet.biomedcentral.com/articles/supplements/volume-20supplement-1.

\section{Authors' contributions}

$\mathrm{SI}$ and AL instigated, designed, coordinated, and supervised the study. MF designed and performed the statistical analysis and contributed to writing the paper. SI wrote the study protocol and selected the SNPS. DO, IP, NV, VT, EK and OF monitored the study, collected clinical data, and isolated DNA. DO and IP genotyped the samples and recorded all data in an Excel database. AB analyzed the prolactin samples. NB and AS supervised the clinical work. SI, AL, and BW supervised the technical work. DO drafted the manuscript. SI and AL supervised the writing. OF, MF, and BW commented on the manuscript. All authors read the paper and agree with its content. All authors read and approved the final manuscript.

\section{Ethics approval and consent to participate}

This work was performed in accordance with The Code of Ethics of the World Medical Association for experiments involving humans (Declaration of Helsinki 1975, revised in Fortaleza, Brazil, 2013). All participants gave their signed informed consent to participate, and the study was approved by the Local Bioethics Committee of the Mental Health Research Institute (protocol N63/7.2014)

\section{Consent for publication}

Not applicable.

\section{Competing interests}

The authors declare that they have no competing interests.

\section{Publisher's Note}

Springer Nature remains neutral with regard to jurisdictional claims in published maps and institutional affiliations.

\section{Author details}

${ }^{1}$ Mental Health Research Institute, Tomsk National Research Medical Center of the Russian Academy of Sciences, Aleutskaya str., 4, Tomsk, Russian Federation634014. ${ }^{2}$ National Research Tomsk State University, Lenin Avenue, Tomsk, Russian Federation36. ${ }^{3}$ Department of Twin Research and Genetic Epidemiology, School of Live Course Sciences, King's College London, Lambeth Palace Road, London SE1 7EH, UK. ${ }^{4}$ Research Institute of Medical Genetics, Tomsk National Research Medical Center of the Russian Academy of Sciences, Naberezhnaya Ushaiki str, Tomsk, Russian Federation10. ${ }^{5}$ National Research Tomsk Polytechnic University, Lenin Avenue, Tomsk, Russian Federation30. ${ }^{6}$ Groningen Research Institute of Pharmacy, PharmacoTherapy, Epidemiology \& Economics, University of Groningen, Antonius Deusinglaan 1, 9713, AV, Groningen, The Netherlands. ${ }^{7} G G Z$ Westelijk Noord-Brabant, Hoofdlaan 8, 4661 AA Halsteren, The Netherlands. ${ }^{8}$ University Medical Center 
Groningen, Department of Clinical Pharmacy and Pharmacology, University of Groningen, Hanzeplein 1, 9713, GZ, Groningen, The Netherlands.

\section{Published: 9 April 2019}

\section{References}

1. van Os J, Kapur S. Schizophrenia. Lancet. 2009;374:635-45. https://doi.org/ 10.1016/S0140-6736(09)60995-8.

2. Ajmal A, Joffe H, Nachtigall LB. Psychotropic-induced hyperprolactinemia: a clinical review. Psychosomatics. 2014;55:29-36. https://doi.org/10.1016/j. psym.2013.08.008.

3. Peuskens J, Pani L, Detraux J, De Hert M. The effects of novel and newly approved antipsychotics on serum prolactin levels: a comprehensive review. CNS Drugs. 2014;28:421-53. https://doi.org/10.1007/s40263-014-0157-3.

4. Haddad PM, Wieck A. Antipsychotic-induced hyperprolactinemia: mechanisms, clinical features, and management. Drugs. 2004;64:2291-314 Available at: https://www.ncbi.n/m.nih.gov/pubmed/15456328.

5. Bushe CJ, Bradley A, Pendlebury J. A review of hyperprolactinaemia and severe mental illness: are there implications for clinical biochemistry? Ann Clin Biochem. 2010;47(Pt 4):292-300. https://doi.org/10.1258/acb.2010. 010025 .

6. Majumdar A, Mangal NS. Hyperprolactinemia. J Hum Reprod Sci. 2013;6: 168-75. https://doi.org/10.4103/0974-1208.121400.

7. Grattan DR. 60 YEARS OF NEUROENDOCRINOLOGY: the hypothalamo-prolactin axis. J Endocrinol. 2015;226:T101-22. https://doi.org/10.1530/JOE-15-0213.

8. Ben-Jonathan N. Dopamine: a prolactin-inhibiting hormone. Endocr Rev. 1985;6:564-89. https://doi.org/10.1210/edrv-6-4-564.

9. Caron MG, Beaulieu M, Raymond V, Gagné B, Drouin J, Lefkowitz RJ, Labrie F. Dopaminergic receptors in the anterior pituitary gland. Correlation of $[3 \mathrm{H}]$ dihydroergocryptine binding with the dopaminergic control of prolactin release. J Biol Chem. 1978;253:2244-53 Available at: http://www. jbc.org/content/253/7/2244.long.

10. Meador-Woodruff JH, Mansour A, Bunzow JR, Van Tol HHM, Watson SJ, Civelli O. Distribution of D2 dopamine receptor mRNA in rat brain. Proc Natl Acad Sci U S A. 1989;86:7625-8 Available at: https://www.ncbi.nlm.nih.gov/ pmc/articles/PMC298119/.

11. Demarest KT, Mckay DW, Riegle GD, Moore KE. Sexual differences in tuberoinfundibular dopamine nerve activity induced by neonatal androgen exposure. Neuroendocrinology. 1981;32:108-13. https://doi.org/10.1159/ 000123140.

12. Gudelsky GA, Porter JC. Release of dopamine from tuberoinfundibular neurons into pituitary stalk blood after prolactin or haloperidol administration. Endocrinology. 1980;106:526-9. https://doi.org/10.1210/ endo-106-2-526.

13. Seeman $P$, Tallerico T. Rapid release of antipsychotic drugs from dopamine D2 receptors: an explanation for low receptor occupancy and early clinical relapse upon withdrawal of clozapine or quetiapine. Am J Psychiatry. 1999; 156(6):876-84. https://doi.org/10.1176/ajp.156.6.876.

14. Linnet K, Ejsing TB. A review on the impact of P-glycoprotein on the penetration of drugs into the brain. Focus on psychotropic drugs. Eur Neuropsychopharmacol. 2008;18(3):157-69. https://doi.org/10.1016/j. euroneuro.2007.06.003.

15. Moons T, de Roo M, Claes S, Dom G. Relationship between P-glycoprotein and second-generation antipsychotics. Pharmacogenomics. 2011;12:1193211. https://doi.org/10.2217/pgs.11.55.

16. Ejsing $T B$, Pedersen $A D$, Linnet K. P-glycoprotein interaction with risperidone and 9-OH-risperidone studied in vitro, in knock-out mice and in drug-drug interaction experiments. Hum Psychopharmacol. 2005;20(7):493-500. https:// doi.org/10.1002/hup.720.

17. Zhu F, Yan CX, Wang Q, Zhu YS, Zhao Y, Huang J, et al. An association study between dopamine D1 receptor gene polymorphisms and the risk of schizophrenia. Brain Res. 2011;1420:106-13. https://doi.org/10.1016/j.brainres. 2011.08.069

18. Grymek K, Jukasiewicz S, Faron-Gyreckaa A, Tworzydlo M, Polit A, Dziedzicka-Wasylewska M. Role of silent polymorphisms within the dopamine D1 receptor associated with schizophrenia on D1-D2 receptor heterodimerization. Pharmacol Rep. 2009;61(6):1024-33 Available at: http:// www.if-pan.krakow.pl/pjp/pdf/2009/6_1024.pdf.

19. Ota VK, Spíndola LN, Gadelha A, dos Santos Filho AF, Santoro ML, Christofolini DM, et al. DRD1 rs4532 polymorphism: a potential pharmacogenomic marker for treatment response to antipsychotic drugs. Schizophr Res. 2012;142(1-3):206-8. https://doi.org/10.1016/j. schres.2012.08.003.

20. De Matos LP, Santana CV, Souza RP. Meta-analysis of dopamine receptor D1 rs4532 polymorphism and susceptibility to antipsychotic treatment response. Psychiatry Res. 2015;229(1-2):586-8. https://doi.org/10.1016/j. psychres.2015.07.054.

21. Zhang Y, Bertolino A, Fazio L, Blasi G, Rampino A, Romano R, et al. Polymorphisms in human dopamine D2 receptor gene affect gene expression, splicing, and neuronal activity during working memory. Proc Natl Acad Sci U S A. 2007;104:20552-7. https://doi.org/10.1073/pnas. 0707106104.

22. Thompson J, Thomas N, Singleton A, Piggott M, Lloyd S, Perry EK, et al. D2 dopamine receptor gene (DRD2) Taq1 A polymorphism: reduced dopamine D2 receptor binding in the human striatum associated with the A1 allele. Pharmacogenetics. 1997;7:479-84 Available at: https://www.ncbi.nlm.nih gov/pubmed/9429233.

23. Dubertret C, Gouya L, Hanoun N, Deybach JC, Ades J, Hamon M, Gorwood P. The $3^{\prime}$ region of the DRD2 gene is involved in genetic susceptibility to schizophrenia. Schizophr Res. 2004;67:75-85. https://doi.org/10.1016/S09209964(03)00220-2.

24. Alenius M, Wadelius M, Dahl ML, Hartvig P, Lindstrom L, HammarlundUdenaes M. Gene polymorphism influencing treatment response in psychotic patients in a naturalistic setting. J Psychiatr Res. 2008:42(11):88493. https://doi.org/10.1016/j.jpsychires.2007.10.007.

25. Lawford BR, Barnes M, Swagell CD, Connor JP, Burton SC, Heslop K, et al. DRD2/ANKK1 Taq1A (rs1800497 C>T) genotypes are associated with susceptibility to second generation antipsychotic-induced akathisia. Schizophr Bull. 2013;39(4):848-56. https://doi.org/10.1177/ 0269881112463469 .

26. Ettinger U, Joober RDE, Guzman R, O'Driscoll GA. Schizotypy, attention deficit hyperactivity disorder, and dopamine genes. Psychiatry Clin Neurosci. 2006;60(6):764-7. https://doi.org/10.1111/j.1440-1819.2006.01594.x.

27. Talkowski ME, Mansour H, Chowdari KV, Wood J, Butler A, Varma PG, et al. Novel, replicated associations between dopamine D3 receptor gene polymorphisms and schizophrenia in two independent samples. Biol Psychiatry. 2006;60:570-7. https://doi.org/10.1016/j.biopsych.2006.04.012.

28. Talkowski ME, Kirov G, Bamne M, Georgieva L, Torres G, Mansour H, et al. A network of dopaminergic gene variations implicated as risk factors for schizophrenia. Hum Mol Genet. 2008;17(5):747-58. https://doi.org/10.1093/ hmg/ddm347.

29. Zhang F, Fan H, Xu Y, Zhang K, Huang X, Zhu Y, et al. Converging evidence implicates the dopamine D3 receptor gene in vulnerability to schizophrenia. Am J Med Genet Part B. 2011;156:613-9. https://doi.org/10.1002/ajmg.b. 31203.

30. Bombin I, Arango C, Mayoral M, Castro-Fornieles J, Gonzalez-Pinto A, Gonzalez-Gomez C, et al. DRD3, but not COMT or DRD2, genotype affects executive functions in healthy and first-episode psychosis adolescents. Am J Med Genet Part B. 2008;147B(6):873-9. https://doi.org/10.1002/ajmg.b.30710.

31. Al Hadithy AF, Ivanova SA, Pechlivanoglou P, Semke A, Fedorenko O, Kornetova E, et al. Tardive dyskinesia and DRD3, HTR2A and HTR2C gene polymorphisms in Russian psychiatric inpatients from Siberia. Prog NeuroPsychopharmacol Biol Psychiatry. 2009;33(3):475-81. https://doi.org/10.1016/ j.pnpbp.2009.01.010.

32. Xu M, Xing Q, Li S, Zheng Y, Wu S, Gao R, et al. Pharmacogenetic effects of dopamine transporter gene polymorphisms on response to chlorpromazine and clozapine and on extrapyramidal syndrome in schizophrenia. Prog Neuro-Psychopharmacol Biol Psychiatry. 2010;34(6):1026-32. https://doi.org/ 10.1016/j.pnpbp.2010.05.017.

33. Tybura P, Trześniowska-Drukała B, Bienkowski P, Beszlej A, Frydecka D, Mierzejewski P, et al. Pharmacogenetics of adverse events in schizophrenia treatment: comparison study of ziprasidone, olanzapine and perazine. Psychiatry Res. 2014;219(2):261-7. https://doi.org/10.1016/j.psychres.2014.05.039.

34. Finberg JP. Update on the pharmacology of selective inhibitors of MAO-A and MAO-B: focus on modulation of CNS monoamine neurotransmitter release. Pharmacol Ther. 2014;143(2):133-52. https://doi.org/10.1016/j. pharmthera.2014.02.010.

35. Manuck SB, Flory JD, Ferrell RE, Mann JJ, Muldoon MF. A regulatory polymorphism of the monoamine oxidase a gene may be associated with variability in aggression, impulsivity, and central nervous system serotonergic responsivity. Psychiatry Res. 2000;95:9-23. https://doi.org/10. 1016/S0165-1781(00)00162-1. 
36. Zivković M, Mihaljević-Peles A, Bozina N, Sagud M, Nikolac-Perkovic M, Vuksan-Cusa B, et al. The association study of polymorphisms in DAT, DRD2, and COMT genes and acute extrapyramidal adverse effects in male schizophrenic patients treated with haloperidol. J Clin Psychopharmacol. 2013;33(5):593-9. https://doi.org/10.1097/JCP.0b013e31829abec9.

37. Terzić T, Kastelic M, Dolžan V, Plesničar BK. Genetic polymorphisms in dopaminergic system and treatment-resistant schizophrenia. Psychiatr Danub. 2016;28(2):127-31 Available at: http://www.psychiatria-danubina. com/UserDocslmages/pdf/dnb_vol28_no2/dnb_vol28_no2_127.pdf

38. Han J, Li Y, Wang X. Potential link between genetic polymorphisms of catechol-O-methyltransferase and dopamine receptors and treatment efficacy of risperidone on schizophrenia. Neuropsychiatr Dis Treat. 2017;13: 2935-43. https://doi.org/10.2147/NDT.S148824 eCollection 2017.

39. Ivanova SA, Osmanova DZ, Boiko AS, Pozhidaev IV, Freidin MB, Fedorenko OY, et al. Prolactin gene polymorphism $(-1149 \mathrm{G} / T)$ is associated with hyperprolactinemia in patients with schizophrenia treated with antipsychotics. Schizophr Res. 2017;182:110-4. https://doi.org/10.1016/j. schres.2016.10.029.

40. Ivanova SA, Osmanova DZ, Freidin MB, Fedorenko OY, Boiko AS, Pozhidaev $\mathrm{N}$, et al. Identification of 5-hydroxytryptamine receptor gene polymorphisms modulating hyperprolactinaemia in antipsychotic drugtreated patients with schizophrenia. World J Biol Psychiatry. 2017;18(3):23946. https://doi.org/10.1080/15622975.2016.1224926.

41. Andreasen NC, Pressler M, Nopoulos P, Miller D, Ho BC. Antipsychotic dose equivalents and dose-years: a standardized method for comparing exposure to different drugs. Biol Psychiatry. 2010;67(3):255-62. https://doi.org/10.1016/ j.biopsych.2009.08.040.

42. Kelly DL, Wehring HJ, Earl AK, Sullivan KM, Dickerson FB, Feldman S, et al. Treating symptomatic hyperprolactinemia in women with schizophrenia: presentation of the ongoing DAAMSEL clinical trial (dopamine partial agonist, aripiprazole, for the Management of Symptomatic ELevated prolactin). BMC Psychiatry. 2013;13:214. https://doi.org/10.1186/1471-244X-13-214.

43. Gonzalez JR, Armengol L, Guino E, Sole X, Moreno V. SNPassoc: SNPs-based whole genome association studies. R package version 1.9-2. 2014, Available at: https://CRAN.R-project.org/package=SNPassoc

44. Katznelson L, Riskind PN, Saxe VC, Klibanski A. Prolactin pulsatile characteristics in postmenopausal women. J Clin Endocrinol Metab. 1998;83: 761-4. https://doi.org/10.1210/jcem.83.3.4675.

45. Maddox PR, Jones DL, Mansel RE. Basal prolactin and total lactogenic hormone levels by microbioassay and immunoassay in normal human sera. Acta Endocrinol (Copenh). 1991;125:621-7 Available at: https://www.ncbi. nlm.nih.gov/pubmed/1789057.

46. Tanner MJ, Hadlow NC, Wardrop R. Variation of female prolactin levels with menopausal status and phase of menstrual cycle. Aust NZJ Obstet Gynaecol. 2011;51:321-4. https://doi.org/10.1111/j.1479-828X.2011.01321.X.

47. Saura J, Kettler R, Da Prada M, Richards JG. Quantitative enzyme radioautography with 3H-Ro 41-1049 and 3H-Ro 19-6327 in vitro: localization and abundance of MAO-A and MAO-B in rat CNS, peripheral organs, and human brain. J Neurosci. 1992;12(5):1977-99. https://doi.org/10. 1523/JNEUROSCI.12-05-01977.1992.

48. Saura J, Bleuel Z, Ulrich J, Mendelowitsch A, Chen K, Shih JC, et al. Molecular neuroanatomy of human monoamine oxidases $a$ and $B$ revealed by quantitative enzyme radioautography and in situ hybridization histochemistry. Neuroscience. 1996;70(3):755-74. https://doi.org/10.1016/S0306-4522(96)83013-2.

49. Kurth JH, Kurth MC, Poduslo SE, Schwankhaus JD. Association of a monoamine oxidase B allele with Parkinson's disease. Ann Neurol. 1993;33: 368-72. https://doi.org/10.1002/ana.410330406.

50. Liu JJ, Wang W, Meng M, Liang CS, Zhang JW. Association between monoamine oxidase B A644G polymorphism and Parkinson's disease risk: a meta-analysis in the Chinese population. Genet Mol Res. 2016;15(2). https:// doi.org/10.4238/gmr.15028349.

51. Yi-Liang W, Li C-X, Li S-B, Liu Y, Lan H. Association study of monoamine oxidase $A / B$ genes and schizophrenia in Han Chinese. Behav Brain Funct. 2011;7:42. https://doi.org/10.1186/1744-9081-7-42.

52. Dlugos AM, Palmer AA, de Wit H. Negative emotionality: monoamine oxidase $B$ gene variants modulate personality traits in healthy humans. J Neural Transm. 2009;1 16:1323-34. https://doi.org/10.1007/s00702-009-0281-2.

53. Gasso P, Bernardo M, Mas S, Crescenti A, Garcia C, Parellada E, et al. Association of $\mathrm{a} / \mathrm{G}$ polymorphism in intron 13 of the monoamine oxidase $B$ gene with schizophrenia in a Spanish population. Neuropsychobiology. 2008:58:65-70. https://doi.org/10.1159/000159774.
54. Kang SG, Park YM, Choi JE, Lim SW, Lee HJ, Lee SH, et al. Association study between antipsychotic-induced restless legs syndrome and polymorphisms of monoamine oxidase genes in schizophrenia. Hum Psychopharmacol. 2010:25(5):397-403. https://doi.org/10.1002/hup.1130.

55. Need AC, Ahmadi KR, Spector TD, Goldstein DB. Obesity is associated with genetic variants that Alter dopamine availability. Ann Hum Genet. 2006;70: 293-303. https://doi.org/10.1111/j.1529-8817.2005.00228.x.

56. Mitsuma T, Rhue H, Hirooka Y, Kayama M, Wago T, Takagi J, et al. Distribution of dopamine transporter in the rat: an Immunohistochemical study. Endocr Regul. 1998:32(2):71-5 Available at: https://www.sav.sk/ journals/endo/full/er0298b.pdf.

57. Demaria JE, Nagy GM, Lerant AA, Fekete MI, Levenson CW, Freeman ME. Dopamine transporters participate in the physiological regulation of prolactin. Endocrinology. 2000;141(1):366-74. https://doi.org/10.1210/endo. 141.1.7281.

58. Bannon MJ, Michelhaugh SK, Wang J, Sacchetti P. The human dopamine transporter gene: gene organization, transcriptional regulation, and potential involvement in neuropsychiatric disorders. Eur Neuropsychopharmacol. 2001; 11:449-55. https://doi.org/10.1016/S0924-977X(01)00122-5.

59. Riddle EL, Fleckenstein AE, Hanson GR. Role of monoamine transporters in mediating psychostimulant effects. AAPS J. 2005;7:E847-51. https://doi.org/ 10.1208/aapsj070481.

60. Sotnikova TD, Beaulieu JM, Gainetdinov RR, Caron MG. Molecular biology, pharmacology and functional role of the plasma membrane dopamine transporter. CNS Neurol Disord Drug Targets. 2006;5:45-56. https://doi.org/ 10.2174/1871527067841111579.

61. Sjoholm H, Bratlid T, Sundsfjord J. 123I-beta-CIT SPECT demonstrates increased presynaptic dopamine transporter binding sites in basal ganglia in vivo in schizophrenia. Psychopharmacology (Berl). 2004;173:27-31. https://doi.org/10.1007/s00213-003-1700-y.

62. Kaur H, Jajodia A, Grover S, Baghel R, Gupta M, Jain S, et al. Genetic variations of PIP4K2A confer vulnerability to poor antipsychotic response in severely ill schizophrenia patients. PLoS One. 2014;9(7):e102556. https://doi. org/10.1371/journal.pone.0102556 eCollection 2014.

Ready to submit your research? Choose BMC and benefit from:

- fast, convenient online submission

- thorough peer review by experienced researchers in your field

- rapid publication on acceptance

- support for research data, including large and complex data types

- gold Open Access which fosters wider collaboration and increased citations

- maximum visibility for your research: over $100 \mathrm{M}$ website views per year

At $\mathrm{BMC}$, research is always in progress.

Learn more biomedcentral.com/submission 